\title{
Right Anterior Temporal Degeneration, Emotions, and Loss of Nonverbal Semantics: Guidelines for Diagnosis of the Emotional Semantic Variant Frontotemporal Dementia
}

Kyan Younes, ${ }^{1}$ Valentina Borghesani, ${ }^{1}$ Maxime Montembeault, ${ }^{1}$ Salvatore Spina, ${ }^{1}$ Maria Luisa Mandelli, ${ }^{1}$ Ariane E. Welch, ${ }^{1}$ Elizabeth Weis, ${ }^{1}$ Patrick Callahan, ${ }^{1}$ Fanny M. Elahi, ${ }^{1}$ Alice Y. Hua, ${ }^{1}$ David C. Perry, ${ }^{1}$ Anna Karydas, ${ }^{1}$ Daniel Geschwind, ${ }^{2}$ Eric Huang, ${ }^{3}$ Lea T. Grinberg, ${ }^{1,3}$ Joel H. Kramer, ${ }^{1}$ Adam L. Boxer, ${ }^{1}$ Gil D. Rabinovici, ${ }^{1}$ Howard J. Rosen, ${ }^{1}$ William W. Seeley, ${ }^{1,3}$ Zachary A. Miller, ${ }^{1}$ Bruce L. Miller, ${ }^{1}$ Virginia E. Sturm,${ }^{1 \dagger}$ Katherine P. Rankin, ${ }^{1 \dagger}$ and Maria Luisa Gorno-Tempini. ${ }^{1,4 \dagger}$

${ }^{1}$ Memory and Aging Center, Department of Neurology, UCSF Weill Institute for Neurosciences, University of California, San Francisco, CA, USA

${ }^{2}$ Neurogenetics Program, Department of Neurology and Semel Institute for Neuroscience and Human Behavior, David Geffen School of Medicine, University of California Los Angeles

${ }^{3}$ Department of Pathology, University of California, San Francisco, CA 94143, USA

${ }^{4}$ Dyslexia Center, University of California, San Francisco

$\uparrow$ These authors contributed equally to this work.

Correspondence to: Kyan Younes, MD.

Address: Sandler Neurosciences Center

675 Nelson Rising Lane, Suite 190

San Francisco, California, 94158

Email: Kyan.Younes@ucsf.edu

Running title: Emotional semantic variant frontotemporal dementia.

Keywords: Right temporal lobe neurodegeneration; semantics, person-knowledge, frontotemporal dementia; FTLD-TDP type C.

Abbreviations: bvFTD = Behavioral variant frontotemporal dementia; esvFTD = Emotional semantic variant frontotemporal dementia; FTD = Frontotemporal dementia; FTLD = Frontotemporal lobar degeneration; rATL = right anterior temporal lobe; SD = Semantic dementia; svPPA = Semantic variant primary progressive aphasia; TDP-43 = transactive respop: phse DNA binding protein 43 
medRxiv preprint doi: https://doi.org/10.1101/2021.06.07.21258432; this version posted June 10, 2021. The copyright holder for this preprint (which was not certified by peer review) is the author/funder, who has granted medRxiv a license to display the preprint in perpetuity.

\section{Abstract:}

Anterior temporal lobe (ATL) degeneration is caused by a pathological process that has a focal onset in the left or right hemisphere. Patients with left-lateralized ATL atrophy typically meet criteria for semantic variant primary progressive aphasia (PPA), a clinical syndrome characterized by loss of verbal semantic knowledge. There is less consensus regarding the symptoms that emerge when atrophy targets the right ATL (rATL), but previous studies have emphasized prosopagnosia as well as alterations in emotion, memory, behavior, and semantic knowledge, symptoms that often lead to a diagnosis of behavioral variant frontotemporal dementia (bvFTD). The goal of the present study was to characterize the cognitive and socioemotional deficits of patients with rATL degeneration in order to refine current conceptualizations of the rATL clinical syndrome.

We identified individuals clinically diagnosed as bvFTD or PPA in our cohort of patients prospectively evaluated for FTD-spectrum disorders. We selected patients who also underwent structural MRI and a comprehensive, multidisciplinary evaluation $(\mathrm{n}=478)$. Based on structural MRI atrophy index, individuals with predominant, rATL atrophy $(n=46)$ were identified and patients with co-occurrence of significant frontal atrophy were excluded. Nineteen patients with rATL degeneration had undergone autopsy. We used the clinical histories to identify early symptoms and examined the cognitive, socioemotional, genetic, and pathological profiles of patients with rATL degeneration.

In patients with rATL degeneration, the most common early clinical symptoms were loss of empathy (27\%), person-specific semantic knowledge (23\%), and complex compulsions (18\%). On socioemotional testing and informant-reported measures, patients exhibited diminished interpersonal warmth, empathy, and emotional theory of mind. Neuropsychological testing revealed deficits in identifying famous people and discriminating facial affect despite preserved face perception. FTLD-TDP was the most frequent pathological correlate of rATL degeneration (84\%), followed by Pick's type (10\%), a subtype of FTLD-tau.

Our results indicate that patients with early, rATL-predominant degeneration present with a behavioral syndrome that results from loss of empathy for others. The underlying mechanism is a progressive loss of semantic knowledge for concepts of social-emotional relevance. We herein refer to this syndrome as "emotional semantic variant frontotemporal dementia." We 
medRxiv preprint doi: https://doi.org/10.1101/2021.06.07.21258432; this version posted June 10, 2021. The copyright holder for this preprint (which was not certified by peer review) is the author/funder, who has granted medRxiv a license to display the preprint in perpetuity.

All rights reserved. No reuse allowed without permission.

propose novel diagnostic criteria for this rATL syndrome in order to facilitate early identification in clinical and research settings. This classification is relevant because, if appropriately diagnosed, these patients most often have FTLD-TDP Type-C pathology.

\section{Introduction}

The term frontotemporal dementia (FTD) was introduced to encapsulate the progressive personality changes, social conduct impairment, and language deficits associated with atrophy of the frontal and temporal lobes. ${ }^{1}$ Within FTD, behavioral symptoms often localize to frontal, temporal, insular, and striatopallidal regions in the right hemisphere, whereas language deficits typically localize to structures in the left. ${ }^{2}$ Currently, the behavioral syndrome associated with FTD is called behavioral variant frontotemporal dementia (bvFTD), and the language disorders are brought together under the term primary progressive aphasia (PPA). ${ }^{3,4}$

The semantic variant of PPA (svPPA, previously called "semantic dementia") is a condition characterized by predominant atrophy of the anterior temporal lobes (ATLs). The ATLs are considered amodal hubs that bind information from primary and association sensory and motor cortices with verbal and non-verbal features into semantic conceptual knowledge that is no longer solely linked to a specific input modality. ${ }^{5-9}$ ATL degeneration is typically caused by FTLD-TDP type $\mathrm{C}$ and results in a variety of language, behavioral, and emotional symptoms over the course of the illness. Early ATL degeneration is often asymmetric, ${ }^{10,11}$ with focal atrophy of either the left ATL (1ATL) or right ATL (rATL). Degeneration soon spreads to the opposite hemisphere, and the clinical symptoms that accompany right- and left-predominant syndromes, therefore, often converge over time. ${ }^{10}$ In individuals with typical hemispheric functional lateralization, the 1ATL and rATL have strong specializations that influence early clinical features. The 1ATL plays a central role in verbal semantic knowledge, such as word comprehension and retrieval, and its atrophy causes classical svPPA. ${ }^{11,12}$ The rATL, in contrast, is critical for nonverbal semantic knowledge. Nonverbal semantic knowledge includes visual semantic association; ${ }^{13}$ sound recognition; ${ }^{14}$ and tactile; ${ }^{15}$ olfactory; ${ }^{16}$ and gustatory stimulus recognition. ${ }^{17}$ Nonverbal semantic processing is also essential for the recognition of familiar and famous people from voices and faces. ${ }^{14,18}$ By linking emotion concepts with verbal associations as well as non-verbal bodily changes (e.g., changes in autonomic nervous system functioning, motor activity, and experience), the rATL is positioned to serve as the core hub for socioemotional semantic processing. ${ }^{9,19,20}$ 
medRxiv preprint doi: https://doi.org/10.1101/2021.06.07.21258432; this version posted June 10, 2021. The copyright holder for this preprint (which was not certified by peer review) is the author/funder, who has granted medRxiv a license to display the preprint in perpetuity.

All rights reserved. No reuse allowed without permission.

Few studies have investigated the clinical characteristics of focal rATL degeneration, but there is strong evidence for early deficits in socioemotional functioning. ${ }^{10,21-25}$ Families and caregivers report prominent behavioral symptoms in patients with rATL degeneration. Diminished empathy — which can include lack of emotional responsiveness as well as decreased social connection and compassion - is often remarkable when atrophy targets the rATL. Neuroimaging studies have associated rATL atrophy to deficits in a wide range of socioemotional functions including informant-reported empathy, ${ }^{26}$ nonverbal social cue (e.g., sarcasm) detection, ${ }^{27}$ and facial emotion recognition. ${ }^{18,28}$ Feelings of familiarity that known others typically elicit may also rely on the rATL, ${ }^{18}$ which suggests that even friends and family members may lose their affective significance to patients with focal rATL atrophy. Although patients with rATL degeneration are often described as having "prosopagnosia", this term does not fully capture the deficit because patients cannot recognize familiar people with either visual or auditory cues (i.e., voices and proper names), indicating a broader semantic deficit for biographical, person-specific semantic knowledge. ${ }^{29}$ This lateralized specialization is observed in patients with typical hemisphere lateralization, however, non-right-handed patients can present with reverse symptomatology due to reverse hemispheric dominance..$^{30,31}$

Despite advances in understanding the lateralized functions of the ATLs, consensus diagnostic criteria for the rATL syndrome are lacking. Patients with rATL atrophy have symptoms that overlap with diagnostic criteria for svPPA, which emphasize verbal semantic deficits, and bvFTD, which focus on behavioral and emotional features. ${ }^{3}$ Because there is no agreement in the field regarding how to classify patients with a rATL syndrome in clinical or research settings, these patients are often identified later in the disease course, and it can be challenging to predict their underlying pathology. The goal of the present study was to examine the characteristics of our cohort of patients with asymmetric rATL atrophy prospectively studied in our multidisciplinary project on FTD-spectrum disorders and to provide a novel set of proposed diagnostic criteria based on a comprehensive assessment of both language and socioemotional functioning.

Our central hypothesis was that loss of non-verbal semantic knowledge due to rATL degeneration would underlie many of the emotional and behavioral symptoms that characterize the rATL syndrome. We hypothesized that lack of empathy would be a prominent feature, and that other bvFTD symptoms (e.g., disinhibition, apathy/inertia, and dysexecutive symptoms) would be less common. We also anticipated that patients with rATL degeneration would have 
medRxiv preprint doi: https://doi.org/10.1101/2021.06.07.21258432; this version posted June 10, 2021. The copyright holder for this preprint (which was not certified by peer review) is the author/funder, who has granted medRxiv a license to display the preprint in perpetuity.

All rights reserved. No reuse allowed without permission.

some characteristic symptoms of svPPA (e.g., word comprehension and confrontational naming difficulties) but that they would often not meet general PPA diagnostic criteria (e.g. aphasia as the most prominent early clinical feature and the principal cause of functional impairment).

\section{Materials and methods}

We identified patients who met bvFTD and/or svPPA criteria (see below) from the University of California, San Francisco (UCSF) Memory and Aging Center (MAC) research cohort with visits between 1998 and $2019(n=682)$. As symptoms were often mild at early research visits, scores on the Clinical Dementia Rating scale (CDR) were not used when determining study inclusion. ${ }^{32}$ Patients who did not have a brain MRI within one year of the first research evaluation were excluded $(n=204)$. From the remaining 478 cases, we used structural neuroimaging measures to identify individuals with predominant rATL atrophy and relative preservation of the frontal lobes (see details below) $(n=46)$. Of these 46 rATL degeneration patients, we later compared those with post-mortem neuropathological data $(n=19$; hereafter: Autopsy Group) to those without neuropathological data ( $n=27$; hereafter: Living Group) Fig. 1. Patients or caregivers provided informed consent following procedures aligned with the Declaration of Helsinki, and the study was approved by the UCSF Committee for Human Research.

\section{Diagnostic criteria:}

Because some patients were diagnosed prior to publication of current diagnostic criteria, two raters, a behavioral neurologist (KY) and a neuropsychologist (MM), reviewed all available medical data to determine whether patients met the following diagnostic criteria: 1.) NearyFTD,$^{33}$ 2.) Neary-Semantic, ${ }^{33}$ 3.) bvFTD,${ }^{3}$ 4.) svPPA. ${ }^{4}$ We also noted whether patients had semantic variant features (i.e., impaired confrontation naming and single-word comprehension) regardless of meeting PPA general criteria (i.e., aphasia is the most prominent deficit in early disease). This allowed us to describe verbal semantic deficits in patients who had predominantly behavioral presentation. ${ }^{4}$ The two raters determined whether each of these criteria was met at three different time points: 1) within the first three years of disease onset; 2) at the first MAC research evaluation, and 3) in the years subsequent to the first MAC evaluation. 


\section{Detailed symptom taxonomy and chronology:}

For each case, we documented early symptoms in the order of their occurrence, as recorded in the histories reported by the patients and their caregivers. We documented each patient's first five symptoms, rather than all symptoms ever noted, because we expected many of the canonical bvFTD symptoms (disinhibition, apathy, loss of empathy, compulsions, hyperorality, and executive deficits) and PPA symptoms (language and semantic impairment) would emerge for most people in the disease's later stages. In an effort to refine our categorization of the behavioral and emotional symptoms, we catalogued symptoms according to the following taxonomy:

1. Empathy deficits: Difficulty recognizing, understanding, or responding to others' emotions and needs; selfishness; emotional distance from others; reduced or inappropriate emotional expressivity.

2. Words and object semantic loss: Loss of knowledge about words, facts, concepts, animate or inanimate objects, places, or landmarks. Patients may demonstrate impaired naming, diminished recall, poor identification, or reduced feelings of familiarity for these domains.

3. Person-specific semantic knowledge loss: Loss of knowledge about known faces, proper names and people (including biographical information about famous people, close friends, and/or family members). Patients may demonstrate impaired naming, diminished recall, poor recognition, or reduced feelings of familiarity for these domains.

4. Complex compulsions and rigidity: Adhering to fixed schedules or roles; preoccupation with dogmas (e.g., hyper-religiosity) or health (hypochondriasis); restricted preference for certain colors, clothing, or diet; hypergraphia; spending hours playing word games and puzzles; repetitive motor or verbal stereotypies; or hoarding.

5. Apathy: Cognitive (reduced planning and voluntary action), behavioral (reduced selfinitiated thoughts and behaviors), and affective (reduced social, emotional, behavioral interest) forms of apathy. ${ }^{34}$

6. Disinhibition: Impulsivity or socially inappropriate behavior.

7. Episodic memory loss: Difficulty remembering events and autobiographical information. 
medRxiv preprint doi: https://doi.org/10.1101/2021.06.07.21258432; this version posted June 10, 2021. The copyright holder for this preprint (which was not certified by peer review) is the author/funder, who has granted medRxiv a license to display the preprint in perpetuity.

All rights reserved. No reuse allowed without permission.

8. Hyperorality or dietary changes: Altered food preferences, Binge eating, increased consumption of alcohol or cigarettes, Oral exploration or consumption of inedible objects.

9. Motor neuron disease signs: Bulbar and limb signs of motor neuron disease.

10. Other symptoms: Visuospatial difficulties, impaired judgment, declined hygiene, loss of sexual desire, weight gain, weight loss, hypersomnia, insomnia. These symptoms are either common in other neurodegenerative illnesses or not specific for a single neurodegenerative disease.

\section{Functional, cognitive, and behavioral assessments:}

Patients underwent a comprehensive multidisciplinary assessment that included functional, neuropsychological, and socioemotional measures Table 1 and Table 2, as previously described. ${ }^{35,36}$ A description of the cognitive battery and further details about patients' performance are presented in the Supplementary material. Verbal semantic knowledge was evaluated with the Peabody Picture Vocabulary Test (PPVT; patients were asked to choose the picture that best describes a word), ${ }^{37}$ the abbreviated 15-item Boston Naming Test (BNT; patients were asked to name different drawings), ${ }^{38}$ and semantic verbal fluency (patients generated as many animals as possible in 60 seconds). Nonverbal semantic knowledge was tested with the picture version of the Pyramids and Palm Trees (PPT-P; patients matched semantically-associated pictures). ${ }^{39}$

We assessed multiple domains of socioemotional functioning with a battery of task-based measures. Visual face perception was evaluated with the Benton Facial Recognition Test, in which patients matched unfamiliar faces, and the identity-matching subtest of the Comprehensive Affect Testing System (CATS), in which patients determined whether pairs of neutral faces were from the same person or different people. ${ }^{40,41}$ The ability to label emotional facial expressions with words was tested with the CATS emotion identification task, in which patients chose the emotion term that matched the facial expression depicted in a photograph from a list of multiple choice options. ${ }^{41}$ On the abbreviated version of the Emotion Evaluation Test (EET) from The Awareness of Social Inference Test (TASIT), patients identified the target emotion from a list of multiple choice options that were displayed by actors in short video clips. 
medRxiv preprint doi: https://doi.org/10.1101/2021.06.07.21258432; this version posted June 10, 2021. The copyright holder for this preprint (which was not certified by peer review) is the author/funder, who has granted medRxiv a license to display the preprint in perpetuity.

All rights reserved. No reuse allowed without permission.

On the TASIT Social Inference-Minimal Test (SIM), patients were asked to detect sarcasm of actors in videos through interpretation of social cues including prosody, facial expression, and gesture. ${ }^{42}$ Theory of mind (ToM) - the ability to infer the thoughts, emotions, and intentions of others-was tested in cognitive (i.e., the ability to identify first and second order object knowledge of actors in videos) and emotional modalities (i.e., the ability to identify first and second order emotion knowledge of actors in videos) using the UCSF ToM Test. ${ }^{43}$ Personspecific semantic knowledge was evaluated using the UCSF Famous Faces Naming test (a free response task in which patients named photographs of famous people's faces), Semantic Famous Face Association test (patients matched famous faces based on their professions), Semantic Famous Name Association test (patients matched written names of famous people based on their professions) and Recognition test (patients chose the famous face among four faces). ${ }^{44}$ Further socioemotional testing details are found in the Supplementary material.

Informant-based measures were also obtained to assess patients' socioemotional behavior in everyday life. Informants rated patients' current cognitive empathy (i.e., perspective taking) and emotional empathy (i.e., empathic concern) using the Interpersonal Reactivity Index (IRI). ${ }^{45}$ Sensitivity and responsiveness to others' subtle emotional expressions were rated by informants using the Revised Self-Monitoring Scale. ${ }^{46}$ Interpersonal warmth and dominance, areas of personality known to be affected in FTD, were evaluated with informant ratings on the Interpersonal Adjective Scales. ${ }^{47}$ Behavioral inhibition (i.e., behaviors associated with response avoidance and sensitivity to threat) and behavioral activation (i.e., behaviors associated with approach motivation including reward responsiveness, drive, and fun-seeking) systems were evaluated with informant ratings on the Behavioral Inhibition System/Behavioral Activation System questionnaire. ${ }^{48}$

\section{Structural neuroimaging analyses:}

We processed structural T1-weighted images, as previously described. ${ }^{49,50} \mathrm{~W}$-maps were generated by comparing each patient's gray matter maps to 534 neurologically healthy controls from the MAC Hillblom Healthy Aging Network (age range 44-99 years, M \pm SD: $68 \cdot 7 \pm 9 \cdot 1$; 220 male/302 female), adjusted for age, sex, total intracranial volume, and magnet field strength. Mean W-score values were extracted for each region of interest (ROI) in the probabilistic Desikan atlas. ${ }^{21} \mathrm{~W}$-scores have a mean value of 0 and an SD of 1 , values of +1.65 and -1.65 correspond to the 95 th and 5 th percentiles, respectively. 
medRxiv preprint doi: https://doi.org/10.1101/2021.06.07.21258432; this version posted June 10, 2021. The copyright holder for this preprint (which was not certified by peer review) is the author/funder, who has granted medRxiv a license to display the preprint in perpetuity.

All rights reserved. No reuse allowed without permission.

Patients were included in the rATL degeneration group if their lowest three $\mathrm{W}$-scores were in right temporal regions, and they had relative preservations of the frontal lobes. For each patient, we calculated the mean $\mathrm{W}$-score of all frontal lobe ROIs and the mean W-score of all right temporal ROIs and computed a proportion with the following index: right temporal index $=$ mean whole frontal w-score/mean right temporal w-score. The rATL degeneration patients who had an index $<0.50$ were included in this study $(n=46) 17$ patients with an index $>0.05$ were excluded Fig. 2 and (Supplementary Table 1).

\section{Statistical analysis:}

Functional, neuropsychological, language, and socioemotional measures Tables 1 and Table 2 were converted to Z-scores using normative healthy control data from previously published MAC studies (details in the Supplementary material) for all measures except for the UCSF ToM test, for which we used unpublished norms from healthy controls in the MAC Hillblom Healthy Aging Network. We used previously published normative scores rather than including a healthy control group in this study due to limitations in obtaining an age- and gender-matched normal control cohort that underwent the same comprehensive language and socioemotional batteries as our rATL cohort. Z-scores 1.5 standard deviations or more below the mean were considered clinically abnormal. Continuous variables in the Autopsy Group and the Living Group were compared using Student's t-test, with $p<0.05$ set as the threshold for statistical significance.

\section{Genetic and neuropathological data}

Forty-one patients ( $89 \%$ of the sample) had genetic data available for the following mutations: PGRN, MAPT, TARDBP, C9orf72, APP, PSEN1, PSEN2, FUS, APOE, and MAPT H1/H2 haplotypes.

In the 19 patients who underwent autopsy, brains were processed and analyzed according to the UCSF Neurodegenerative Disease Brain Bank protocol. ${ }^{51}$ In short, eight micro-thick formalin-fixed paraffin-embedded tissue sections from 23 tissue blocks were cut to represent 27 regions of interest. All blocks underwent routine hematoxylin and eosin staining, and subsets underwent immunohistochemistry for hyperphosphorylated tau, amyloid- $\beta$, TDP-43, alpha-synuclein, and 3R-tau antibodies. Neuropathological diagnoses were based on consensus criteria. $^{52-54}$ 
medRxiv preprint doi: https://doi.org/10.1101/2021.06.07.21258432; this version posted June 10, 2021. The copyright holder for this preprint

\section{Data availability}

The data for this study is available upon request.

\section{Results}

\section{Demographic features}

Table 1 shows the demographic information. In the full rATL cohort $(n=46)$, the average age of onset was 60.2 years (standard deviation $[\mathrm{SD}]=6.8$ years), and the average age at the first research evaluation was 66.7 years $(\mathrm{SD}=8.4) .52 \%$ of the patients were men and $15 \%$ were non-right-handed. Patients were highly educated with an average of 16.5 years of education $(\mathrm{SD}=3.6) .91 \%$ were White and $9 \%$ were Chinese. On average, patients were in the mild to moderate range of disease severity; at the first research visit, the average Mini-Mental State Exam score was $25.7 / 30(\mathrm{SD}=5.2)$, and on the CDR the average score was $0.9 / 3(\mathrm{SD}=0.5)$.

\section{Diagnostic criteria and clinical symptom chronology}

During the first three years of the illness, only a minority of patients in the rATL group met diagnostic criteria for Neary-FTD (13\%), Neary-SD (9\%), bvFTD (27\%), or svPPA (13\%). Approximately one third had semantic variant features but did not meet criteria for svPPA $(36 \%)$. At the time of the first research evaluation at the MAC (average 5.3 years after disease onset), these percentages were higher: Neary-FTD (52\%), Neary-SD (11\%), bvFTD (83\%), svPPA (16\%), and semantic variant features (78\%) (Supplemental Table 3).

The clinical histories revealed that, when combining all symptoms that happened during the first three years of the illness, the most common symptoms for patients with rATL degeneration were loss of empathy (27\%), loss of person-specific semantic knowledge (23\%), complex compulsions and rigidity (18\%), and loss of verbal semantic knowledge (13\%) Fig. 3. The sequence of the first two symptoms in all patients is shown in Supplemental table 4.

Caregiver-reported examples of loss of empathy included decline in the ability to understand and respond to others' emotions and needs (e.g., not consoling a family member who lost a parent or was diagnosed with a terminal illness, making tactless comments in a funeral, asking a crying child why their eyes were watering, and becoming more self-centered. Often loss of 
medRxiv preprint doi: https://doi.org/10.1101/2021.06.07.21258432; this version posted June 10, 2021. The copyright holder for this preprint (which was not certified by peer review) is the author/funder, who has granted medRxiv a license to display the preprint in perpetuity.

All rights reserved. No reuse allowed without permission.

empathy toward others is interpreted by caregivers as selfishness. Examples of loss of personspecific semantic knowledge included not recognizing familiar people by the face or voice, not recalling biographical information of a famous person, and not knowing their relationship to familiar people. Examples of complex compulsions and rigidity included preoccupation behavior including sticking to rigid time schedules, dogmatism, hypergraphia, hypochondriasis, restricted preference to certain colors, clothing or diet, games and puzzles. Less commonly they exhibited simple repetitive motor or speech behaviors or hoarding behaviors. Examples of loss of verbal semantics included difficulty understanding word meaning or recognizing objects.

When patients had both person-specific semantic knowledge and verbal semantic loss (32 patients $(69 \%))$, the person-specific semantic knowledge symptoms were reported to precede the verbal semantic complaints in 24 patients $(75 \%)$. Five patients $(10 \%)$ had person-specific semantic knowledge symptoms without verbal semantic complaints and 6 patients $(14 \%)$ had verbal semantic complaints without person-specific semantic knowledge complaints. Only three patients $(6 \%)$ had neither person-specific semantic knowledge nor verbal semantic complaints.

While these first four most common symptoms emerged within the first three years of disease onset, the later symptoms (fifth, sixth, and beyond, often did not occur until more advanced stages. After four years of disease progression, common symptoms included apathy and disinhibition. For these two symptoms, differences in reporting created ambiguity. Apathy was explicitly documented in the history as a complaint of 11 patients, whereas on the NPI (Supplementary Table 2), apathy was coded in 39 patients. The item of apathy on the NPI appeared mainly in the context of affective-emotional apathy questions, and thus could also be interpreted as loss of empathy. On history, disinhibition was reported in 23 patients whereas on the NPI it was coded in 36 patients. In the majority of patients, disinhibition appeared as insensitivity to social context rather than as an impulse-control deficit. By history, episodic memory impairment, executive symptoms, dietary changes, motor neuron disease, and problems navigating were less frequent and happened later in the disease course. Five patients $(11 \%)$ had loss of sexual desire, two as an early symptom. However, this was reported in the context of emotional changes and loss of interest to other social activities. Irritability was reported in eight patients (17\%), and as an early symptom only in three patients $(6 \%)$. The majority of changes in eating behavior included rigid eating habits 
medRxiv preprint doi: https://doi.org/10.1101/2021.06.07.21258432; this version posted June 10, 2021. The copyright holder for this preprint (which was not certified by peer review) is the author/funder, who has granted medRxiv a license to display the preprint in perpetuity.

All rights reserved. No reuse allowed without permission.

and restricted diets (12 patients; 26\%), increased eating ( 7 patients, $8 \%$ ) was reported in the context of other compulsive behaviors and did not reach the degree of binge eating or oral exploration or consumption of inedible objects. Sleep changes, increased or decreased sleep, happened in five cases $(10 \%)$, three of which were in the first year of disease onset.

\section{Functional, cognitive, and behavioral results}

Neuropsychological testing Table 1 and Table 2 demonstrated that, at presentation to the MAC, patients with rATL degeneration patients had severe impairment in both verbal semantic knowledge (on the BNT and PPVT) and nonverbal (visual) semantic knowledge (on the PPTP). They also had deficits in verbal fluency, with more significant impairment in semantic than in lexical fluency, and on other tests of executive functioning. Although episodic memory was also impaired, visuospatial processing was intact.

On tests of socioemotional functioning, rATL degeneration patients had severe deficits in multiple domains. On the CATS, a static face perception test, although they had no difficulty with face identity-matching, their emotion labeling was impaired, suggesting a deficit in emotion recognition. Patients also had difficulty labeling the emotions of others in videos (TASIT-EET) and understanding paralinguistic cues (TASIT-SIM-M). On tests of ToM, patients had normal cognitive ToM scores but impaired emotional ToM scores, indicating poor comprehension of others' emotional, but not cognitive, states. On the Famous Faces test, rATL degeneration patients could not identify the faces, the names, or the occupations of famous people. Using two different stimuli, headshots or written names of famous faces, rATL patients could not match people who had the same occupation indicating loss of person-specific semantic knowledge rather than prosopagnosia. Many patients demonstrated severe impairment on the Confrontation Naming, Familiarity for both pictures and names of famous people, and Semantic Association subtests, which suggested widespread deficits in personspecific semantic knowledge as assessed with both verbal and non-verbal stimuli.

On informant-based measures, rATL degeneration patients had abnormal scores on multiple measures of behavior and personality. Patients had very low emotional empathy (IRI Empathic Concern), cognitive empathy (IRI Perspective Taking), and socioemotional sensitivity (RSMS). On personality measures, informants rated patients as having low levels of interpersonal warmth yet they showed preserved dominance (IAS). On the Behavioral Activation System subscales, patients were described as having low fun-seeking (BAS -FS), 
medRxiv preprint doi: https://doi.org/10.1101/2021.06.07.21258432; this version posted June 10, 2021. The copyright holder for this preprint (which was not certified by peer review) is the author/funder, who has granted medRxiv a license to display the preprint in perpetuity.

All rights reserved. No reuse allowed without permission.

suggesting that they had little interest in approaching potentially enjoyable events. By contrast they exhibited, normal reward sensitivity (BAS-RR) and drive (BAS-D). On the Behavioral Inhibition System subscale, patients' sensitivity to social threats, such as punishment (BIS), was in the normal range.

\section{Genetic and pathology results}

None of the patients in the Autopsy Group (available genetic data $n=18,94 \%$ ) carried genetic mutations, including the two cases with motor neuron disease (MND). One patient had FTLDTDP-unspecified subtype with MND; although this person had a positive family history of dementia and MND, the genetic panel was negative including for C9orf72, GRN, MAPT, TDP43, and FUS. In the Living Group (available genetic data $\mathrm{n}=23,81 \%$ ), none of the patients carried genetic mutations except for one patient presenting with a TARDBP genetic mutation. $A P O E$ data were available in 40 cases $(55 \% \mathrm{E} 3 / \mathrm{E} 3 ; 22 \% \mathrm{E} 3 / \mathrm{E} 4 ; 18 \% \mathrm{E} 2 / \mathrm{E} 3)$.

Most of the patients in the Autopsy Group had FTLD-TDP type C pathology (68\%). When considering all types of FTLD-TDP cases, regardless of the neuropathological subtype, the percentage increased (84\%). Three patients had FTLD-tau, two patients had FTLD-tau Pick's type, and one patient had FTLD-tau unclassifiable 4R tauopathy. In the Autopsy Group, only three patients did not have loss of semantic knowledge on history or testing. Interestingly, none of these three cases had FTLD-TDP type C (two had FTLD-tau Pick's type, and one had FTLDTDP type B). See Table 3 and (Supplementary Table 5) for the pathology results.

\section{Discussion}

Our results suggest that loss of semantic knowledge for socioemotional concepts is the primary mechanism underlying both behavioral and cognitive symptoms in patients with selective rATL atrophy. Patients with degeneration of the rATL demonstrated early loss of empathy and person-specific semantic knowledge (i.e., mainly face-based, non-verbal semantic knowledge) as well as complex compulsions and loss of verbal semantic knowledge. Later in the disease, patients developed apathy and disinhibition. Consistent with previous neuropathological studies, ${ }^{55,56}$ this constellation of symptoms reflects dysfunction in underlying neuroanatomical systems that overlap with but are dissociable from those involved in bvFTD. The pathological correlate of this anatomy is usually FTLD-TDP pathology, most often, FTLD-TDP type C. We 
medRxiv preprint doi: https://doi.org/10.1101/2021.06.07.21258432; this version posted June 10, 2021. The copyright holder for this preprint (which was not certified by peer review) is the author/funder, who has granted medRxiv a license to display the preprint in perpetuity.

All rights reserved. No reuse allowed without permission.

propose that rATL degeneration disrupts neural representations of multimodal socioemotional semantic knowledge that results in prominent deficits in empathy, emotion, and social behavior. As such, this syndrome necessitates a distinct nomenclature, which herein we refer to as "emotional semantic variant frontotemporal dementia" (esvFTD). Below, we discuss the unique features of rATL degeneration and propose a novel diagnostic classification to capture this disorder in its early stages and to differentiate it from the initially aphasic (svPPA) or predominantly behavioral (bvFTD) syndromes.

The ability to recognize people and their emotions requires mostly non-verbal socioemotional semantic knowledge. The rATL represents the sensorimotor activities, visceral changes, and subjective experiences that arise in response to emotional stimuli, comprising facial expressions, into multimodal semantic concepts. ${ }^{9,19}$ Identification of known people from their face or voice requires person-specific semantic knowledge that incorporates visual and auditory information about what they look and sound like with biographical information about who they are and their relation to the observer. In contrast to classical prosopagnosia, the visual inability to recognize familiar people from their faces only, loss of person-specific semantic knowledge refers to loss of multimodal information about familiar people including information about their face, name, voice, biography, and relationship to the patient. ${ }^{14,18}$ Understanding others' feelings, too, requires semantic knowledge about nonverbal stimuli (tone of voice, body position, facial expression) as well as access to autonomic, bodily cues that foster vicarious experience of others' internal states. ${ }^{57,58}$ We expected that rATL degeneration would disrupt socioemotional semantic knowledge and, thus, interfere with the ability to recognize familiar others and to attribute meaning to their emotional expressions. ${ }^{10,25,26,44,55}$ In turn, the inability to recognize other's emotions and their values would result in inappropriate behaviors that are not suitable to the prevailing context.

Consistent with our hypotheses, patients with rATL degeneration displayed prominent deficits in empathy and person-specific semantic knowledge. Family members reported that patients with rATL degeneration often exhibited increased interpersonal distance and coldness and decreased responsivity to others' emotions. These real-world symptoms suggested deficits in multiple empathy-related subprocesses, which were also evident in both informant-based questionnaires and socioemotional testing. Informants who had been close to the patient before disease onset reported reductions in cognitive and emotional empathy, lack of responsiveness to other`s emotional expressions, and reduced interpersonal warmth, although interpersonal 
medRxiv preprint doi: https://doi.org/10.1101/2021.06.07.21258432; this version posted June 10, 2021. The copyright holder for this preprint (which was not certified by peer review) is the author/funder, who has granted medRxiv a license to display the preprint in perpetuity.

All rights reserved. No reuse allowed without permission.

dominance was preserved. On socioemotional testing, patients showed difficulty selecting a label for facial emotional expressions on the CATS emotion identification task, despite preserved face perception on CATS face identity-matching and Benton Face Recognition tests. These findings suggest impaired ability to understand the meaning of observed facial expressions and are consistent with literature showing disrupted face processing in both svPPA and right temporal patients. ${ }^{59}$ Patients with rATL degeneration also had difficulty labeling emotions in videos of socioemotional scenarios on the TASIT-EET, even though the videos combined facial, prosodic, postural and gestural emotional cues, suggesting a multimodal nonverbal loss of the ability to fully comprehend emotional cues. Moreover, patients were impaired at interpreting videos that tested emotional ToM, despite those emotions being explicitly labeled for them throughout the task. Of note is that patients had no trouble interpreting cognitive ToM videos that relied on perspective-taking focused on physical objects rather than on others' changing emotions. This suggests that rATL patients' deficits were specifically due to problems with thinking about emotions, rather than a result of task-specific non-emotional cognitive demands, and showed that their emotion comprehension deficits extend deeper than the retrieval of the name of the emotion.

Loss of person-specific semantic knowledge was corroborated objectively by severe impairment on the Famous Faces Naming, Semantic Association, and Familiarity tasks, as previously reported. ${ }^{60}$ Patients also had severe impairment identifying famous people from their proper names, indicating that their deficit goes beyond classical prosopagnosia and represents a multimodal semantic loss for person-specific concepts. The high frequency of the first two symptoms in our cohort (loss of empathy and person-specific semantic knowledge) and the deficits on both facial emotion identification and famous faces, despite preserved face perception, led us to hypothesize that the brain regions subserving face and emotion processing are closely interlinked and are likely to undergo inter-dependent development during maturation, and consequently, concordant decay during neurodegeneration. Neurodevelopmentally, the ability to acquire and respond to social and emotional concepts is linked to accurate interpretation of emotional expressions during early childhood. In fact, recognition of emotional facial expressions is a fundamental aspect of human behavioral neurodevelopment, as infants prefer to look at faces from a very early age and regulate their actions based on maternal emotional facial expressions. ${ }^{61}$ Furthermore, impairment in recognizing emotional facial expressions is presumed to be one of the mechanisms underpinning the behavioral changes in autism spectrum disorder which involves the rATL. ${ }^{62}$ 
medRxiv preprint doi: https://doi.org/10.1101/2021.06.07.21258432; this version posted June 10, 2021. The copyright holder for this preprint (which was not certified by peer review) is the author/funder, who has granted medRxiv a license to display the preprint in perpetuity.

All rights reserved. No reuse allowed without permission.

rATL patients most commonly exhibited complex, goal-oriented, and time-consuming behaviors that reflected cognitive rigidity. In the later phases of disease, patients with rATL degeneration also exhibited apathy and disinhibition, symptoms that are cardinal features of bvFTD. In bvFTD, apathy can reflect underlying deficits in cognitive, behavioral, or affective systems that are anchored by the frontal lobes. ${ }^{34}$ Disinhibition in bvFTD can refer to behaviors that reflect a lack of impulse control, imbalanced reward and punishment systems, executive dysfunction, lack of disgust, or difficulty understanding emotional contexts. ${ }^{63}$ The clinical histories of patients in our cohort suggested that symptoms recorded as apathy and disinhibition differed from typical examples reported in bvFTD. For instance, lack of participation in activities with family or making tactless comments were due to socioemotional semantic deficits rather than apathy or impaired impulse control. By history, the rATL degeneration patients had early loss of interest in friends and family, were less affectionate, and made tactless comments indicating a disregard for the social context but did not show deficits in impulse control until after year four of illness.

Although loss of empathy is the most common discrete symptom used by clinicians and caregivers to describe the early stages, a previous study suggested a prodromal phase of irritability, emotional distance, and changes in sleep, appetite, and libido. ${ }^{10}$ In this study we considered the subtle early emotional changes such as becoming more selfish and emotionally distant as part of loss of empathy as these symptoms are likely the subtle early manifestations of socioemotional semantic loss. Libido changes and irritability happened in the context of loss of empathy. Similarly, appetite changes happened in the context of other complex compulsions. Sleep changes happened as a prodromal symptom only in a minority of patients. It is possible that the prevalence of these symptoms is underestimated because of the more pressing symptoms by the time patients present for evaluation.

Based on previous evidence from cognitive neuroscience and the data presented here, we speculate that primary underlying cause of these interpersonal deficits is loss of socioemotional semantic knowledge, and propose the new name of "emotional semantic variant of FTD (esvFTD). The intention of using this name is to point to both the clinical and cognitive/anatomical mechanism of the syndrome rather than using an anatomical label, such as in "right temporal" variant.

The right and left ATL syndromes are considered lateralized manifestations of a common neurodegenerative process. Here, we propose a novel diagnostic criteria for rATL degeneration 
medRxiv preprint doi: https://doi.org/10.1101/2021.06.07.21258432; this version posted June 10, 2021. The copyright holder for this preprint (which was not certified by peer review) is the author/funder, who has granted medRxiv a license to display the preprint in perpetuity.

All rights reserved. No reuse allowed without permission.

that will help distinguish patients with predominant rATL atrophy from those whose atrophy is mainly in the 1ATL. In our clinical criteria for rATL degeneration, loss of nonverbal socioemotional semantic knowledge is the central deficit (Table 4). The core features include loss of empathy, difficulty identifying and naming known people, and complex compulsions or rigid thought process. Supportive features include object naming difficulties, spared visuospatial functions, motor speech, and phonology. A diagnosis of probable esvFTD also requires supportive neuroimaging results in which there is disproportionate rATL atrophy or hypometabolism.

In this rATL cohort, there was a relatively high prevalence of non-right handedness $(15 \%)$ compared to the $10 \%$ reported in the general population. ${ }^{64}$ This high prevalence of non-right handedness, and associated atypical language and socioemotional processes, might explain why verbal semantic symptoms preceded the non-verbal ones in some of the patients in our cohort. Previous studies suggest that non-right-handedness is over-represented in svPPA compared to other PPA variants and to the general population. ${ }^{65} \mathrm{~A}$ previous case report described a behavioral presentation in a non-right-handed patient who had left temporal predominant atrophy. ${ }^{30}$ Our findings suggest that non-right handedness prevalence is also high in rATL degeneration, consistent with the hypothesis that developmental asymmetries might be associated with vulnerability to neurodegenerative illnesses. ${ }^{65,66}$

While other diagnostic frameworks for rATL degeneration have been proposed, our large sample size, prospective evaluation and comprehensive socioemotional testing battery enabled us to derive a more complete and precise depiction of symptoms and mechanisms typical of this syndrome. One recently proposed diagnostic framework for rATL degeneration identified memory deficits as a core symptom, considered only prosopagnosia rather than the broader concept of loss of person-specific semantic knowledge, and combined all behavioral symptoms including loss of empathy, compulsions, apathy, and disinhibition, focusing on a singular behavior deficit rather than examining their distinct manifestations and underlying mechanisms. ${ }^{26}$ Literature on rATL degeneration observes semantic memory loss but not episodic memory deficits, ${ }^{3,27,28}$ and when episodic memory deficits were reported it was either not a prominent feature, ${ }^{8}$ or comorbid AD pathology was not an exclusionary factor. ${ }^{29}$ Similarly, in our study patients with rATL degeneration did not exhibit florid episodic memory difficulties and their memory complaints were often driven by their semantic memory deficit. Moreover, including episodic memory deficits as a core diagnostic criterion for rATL 
medRxiv preprint doi: https://doi.org/10.1101/2021.06.07.21258432; this version posted June 10, 2021. The copyright holder for this preprint (which was not certified by peer review) is the author/funder, who has granted medRxiv a license to display the preprint in perpetuity.

All rights reserved. No reuse allowed without permission.

degeneration syndrome is likely to cause significant conflation with the clinical AD syndrome, particularly in settings where AD biomarkers are unavailable.

With regards to limitations, our imaging-based selection criteria focused on right temporal predominant atrophy with relatively preserved frontal volume. Thus, we excluded cases that had both predominant right temporal and concomitant severe frontal atrophy. Additional work to phenotype this subset of FTD patients with right-lateralized temporal and frontal damage, likely caused by Pick's disease, would be of value. Another limitation is that patients presented on average five years after estimated disease onset, and as a result we had to rely on the recollection of early symptoms from themselves and their informants. It is our hope that these diagnostic criteria for rATL degeneration syndrome will facilitate identification of these patients earlier in the disease course, allowing for direct evaluation of early symptoms and support for our report-based findings in independent samples. Additionally, without including svPPA and bvFTD patients for comparison, we cannot comment here on the sensitivity and specificity of the proposed criteria, though this can now be a focus of future studies. Finally, the patients in our cohort are mostly White and highly educated. Further studies inclusive of diverse patient population can shed light on the cultural and environmental variability of socioemotional presentations in patients with rATL degeneration.

In conclusion, we show that patients with rATL degeneration have a unique clinical progression of symptoms that underscores early and focal damage to the neural systems underlying socioemotional and mainly non-verbal semantic knowledge. The deficits resulting from rATL degeneration can be captured by specific neuropsychological tests that investigate knowledge of emotions and individual people. In an effort to improve precise communication, we propose the term esvFTD because of its descriptive value as it emphasizes the major distinguishing features of this illness. We believe that this term will help patients, caregivers, and providers dealing with this illness. Accurate identification of esvFTD patients will pave the way to better prognostication and therapeutics, as well as to further understanding of the role of nonverbal semantics in human social behavior. The results of this study contribute to the phenomenological characterization of FTD-spectrum disorders and support the diagnostic value of identifying early symptoms and marking their chronological progression. 
medRxiv preprint doi: https://doi.org/10.1101/2021.06.07.21258432; this version posted June 10, 2021. The copyright holder for this preprint (which was not certified by peer review) is the author/funder, who has granted medRxiv a license to display the preprint in perpetuity.

\section{Acknowledgements}

The authors thank the research patients and their families for the time and effort they dedicated to research at UCSF's Memory and Aging Center. VBM analyses were performed using the Brainsight system, developed at UCSF by Katherine P. Rankin, Cosmo Mielke, and Paul Sukhanov, and powered by the VLSM script written by Stephen M. Wilson, with funding from the Rainwater Charitable Foundation and the UCSF Chancellors Fund for Precision Medicine. We thank Anna Karydas and Jennifer Yokoyama (UCSF Memory and Aging Center genetics experts) for assistance with genetic data, as well as Dr. John Trojanowski (Department of Pathology and Laboratory Medicine, University of Pennsylvania. Pennsylvania, Philadelphia) for assistance with autopsy data,.

\section{Funding}

This work was funded by the National Institutes of Health (NINDS R01NS050915, NIDCD K24DC015544, NIDCD R03DC013403, NIDCD F32DC009145, NIA U01AG052943, NIA P50AG023501, NIA P01AG019724, NIA R01AG038791, NINDS U54NS092089, NIA K08AG052648, NIA R01AG029577, NIA K23-AG021606, NIA P50AG023501), Alzheimer's Disease Research Center of California (03- 75271 DHS/ADP/ARCC); Larry L. Hillblom Foundation; John Douglas French Alzheimer's Foundation; Koret Family Foundation; Consortium for Frontotemporal Dementia Research; and McBean Family Foundation. LTG is partially funded by NIH K24AG053435. These supporting sources were not involved in the study design, collection, analysis or interpretation of data, nor were they involved in writing the paper or in the decision to submit this report for publication.

\section{Competing interests}

The authors declare that they have no known competing financial interests or personal relationships that could have appeared to influence the work reported in this paper. 


\section{References:}

1. Neary D, Brun A, Englund B, et al. Clinical and neuropathological criteria for frontotemporal dementia. J Neurol Neurosurg Psychiatry. 1994;57(4):416-418. doi:10.1136/jnnp.57.4.416

2. Miller BL, Chang L, Mena I, Boone K, Lesser IM. Progressive right frontotemporal degeneration: clinical, neuropsychological and SPECT characteristics. Dementia. 1993;4(3-4):204-213. doi:10.1159/000107324

3. Rascovsky K, Hodges JR, Knopman D, et al. Sensitivity of revised diagnostic criteria for the behavioural variant of frontotemporal dementia. Brain. 2011;134(Pt 9):2456-2477. doi:10.1093/brain/awr179

4. Gorno-Tempini ML, Hillis AE, Weintraub S, et al. Classification of primary progressive aphasia and its variants. Neurology. 2011;76(11):1006-1014. doi:10.1212/WNL.0b013e31821103e6

5. Guo CC, Gorno-Tempini ML, Gesierich B, et al. Anterior temporal lobe degeneration produces widespread network-driven dysfunction. Brain. 2013;136(10):2979-2991. doi:10.1093/brain/awt222

6. Mummery CJ, Patterson K, Price CJ, Ashburner J, Frackowiak RS, Hodges JR. A voxel-based morphometry study of semantic demntia: relationship between temporal lobe atrophy and semantic memory. Ann Neurol. 2000;47(1):36-45. http://www.ncbi.nlm.nih.gov/htbinpost/Entrez/query?db=m\&form=6\&dopt=r\&uid=10632099.

7. Patterson K, Nestor PJ, Rogers TT. Where do you know what you know? The representation of semantic knowledge in the human brain. Nat Rev Neurosci. 2007;8(12):976-987. doi:10.1038/nrn2277

8. Hodges JR, Patterson K. Semantic memory disorders. Trends Cogn Sci. 1997;1(2):68-72. doi:10.1016/S1364-6613(97)01022-X

9. Ralph MAL, Jefferies E, Patterson K. The neural and computational bases of semantic cognition. Nat Publ Gr. 2016;18(1):42-55. doi:10.1038/nrn.2016.150

10. Seeley WW, Bauer AM, Miller BL, et al. The natural history of temporal variant frontotemporal dementia. Neurology. 2005;64(8):1384-1390. doi:10.1212/01.WNL.0000158425.46019.5C

11. Borghesani V, Battistella G, Mandelli ML, et al. Regional and hemispheric susceptibility of the temporal lobe to FTLD-TDP type C pathology. NeuroImage Clin. 2020;28(November 2019):102369. doi:10.1016/j.nicl.2020.102369

12. Hodges JR, Patterson K, Oxbury S, Funnell E. Semantic dementia. Progressive fluent aphasia with temporal lobe atrophy. Brain. 1992;115(Pt 6):1783-1806.

13. Snowden JS, Griffiths HL, Neary D. Semantic-episodic memory interactions in semantic dementia: Implications for retrograde memory function. Cogn Neuropsychol. 1996;13(8):1101-1139. doi:10.1080/026432996381674

14. Luzzi S, Baldinelli S, Ranaldi V, et al. Famous faces and voices: Differential profiles in early right and left semantic dementia and in Alzheimer's disease. Neuropsychologia. 2017;94(November 2016):118128. doi:10.1016/j.neuropsychologia.2016.11.020

15. Hoffman P, Jones RW, Ralph MAL. The degraded concept representation system in semantic dementia: Damage to pan-modal hub, then visual spoke. Brain. 2012;135(12):3770-3780. doi:10.1093/brain/aws282

16. Luzzi S, Snowden JS, Neary D, Coccia M, Provinciali L, Lambon Ralph MA. Distinct patterns of olfactory impairment in Alzheimer's disease, semantic dementia, frontotemporal dementia, and corticobasal degeneration. Neuropsychologia. 2007;45(8):1823-1831. doi:10.1016/j.neuropsychologia.2006.12.008

17. Piwnica-Worms KE, Omar R, Hailstone JC, Warren JD. Flavour processing in semantic dementia. Cortex. 2010;46(6):761-768. doi:10.1016/j.cortex.2009.07.002

18. Gainotti G. Different patterns of famous people recognition disorders in patients with right and left anterior temporal lesions: A systematic review. Neuropsychologia. 2007;45(8):1591-1607. doi:10.1016/j.neuropsychologia.2006.12.013

19. Winkielman P, Coulson S, Niedenthal P. Dynamic grounding of emotion concepts. Philos Trans $R$ Soc B Biol Sci. 2018;373(1752). doi:10.1098/rstb.2017.0127 
20. Binney RJ, Ramsey R. Controlled Social Cognition: the role of conceptual knowledge and cognitive control in a neurobiological model of the social brain. PsyArXiv Prepr. 2019:1-45.

21. Edwards-Lee T, Miller BL, Benson DF, et al. The temporal variant of frontotemporal dementia. Brain. 1997;120(Pt 6):1027-40.

22. Gorno-Tempini ML, Dronkers NF, Rankin KP, et al. Cognition and anatomy in three variants of primary progressive aphasia. Ann Neurol. 2004;55(3):335-346.

http://www.ncbi.nlm.nih.gov/entrez/query.fcgi? $\mathrm{cmd}=$ Retrieve \&db=PubMed\&dopt=Citation\&list_uids= 14991811.

23. Perry RJ, Hodges JR. Differentiating frontal and temporal variant frontotemporal dementia from Alzheimer's disease. Neurology. 2000;54(12):2277-2284.

24. Chan D, Anderson V, Pijnenburg Y, et al. The clinical profile of right temporal lobe atrophy. Brain. 2009;132(5):1287-1298. doi:10.1093/brain/awp037

25. Kumfor F, Landin-Romero R, Devenney E, et al. On the right side? A longitudinal study of left-versus right-lateralized semantic dementia. Brain. 2016;139(3):986-998. doi:10.1093/brain/awv387

26. Rankin Katherine.P., Gorno-Tempini Luisa. M, Stephen.C. A, et al. Structural anatomy of empathy in neurodegenerative disease. Brain. 2006;129(11):2945-2956. doi:10.1093/brain/awl254

27. Rankin KP, Salazar A, Gorno-Tempini ML, et al. Detecting sarcasm from paralinguistic cues: Anatomic and cognitive correlates in neurodegenerative disease. Neuroimage. 2009;47(4):2005-2015. doi:10.1016/j.neuroimage.2009.05.077

28. Irish M, Kumfor F, Hodges JR, Piguet O. A tale of two hemispheres: contrasting socioemotional dysfunction in right- versus left-lateralised semantic dementia. Dement Neuropsychol. 2013;7(1):88-95. doi:10.1590/S1980-57642013DN70100014

29. Joubert S, Felician O, Barbeau E, et al. The right temporal lobe variant of frontotemporal dementia : Cognitive and neuroanatomical profile of three patients. J Neurol. 2006.

http://www.ncbi.nlm.nih.gov/entrez/query.fcgi? $\mathrm{cmd}=$ Retrieve \&db=PubMed\&dopt=Citation\&list_uids= 16773268

30. Miller ZA, Hinkley LB, Herman A, et al. Anomalous functional language lateralization in semantic variant PPA. Neurology. 2015;84(2):204-206. doi:10.1212/WNL.0000000000001131

31. Perry RJ, Rosen HR, Kramer JH, Beer JS, Levenson RL, Miller BL. Hemispheric dominance for emotions, empathy and social behaviour: evidence from right and left handers with frontotemporal dementia. Neurocase. 2001;7(2):145-160.

32. Morris JC. The Clinical Dementia Rating (CDR): current version and scoring rules [see comments]. Neurology. 1993;43(11):2412-2414.

33. Neary D, Snowden JS, Gustafson L, et al. Frontotemporal lobar degeneration: a consensus on clinical diagnostic criteria. Neurology. 1998;51(6):1546-1554. doi:10.1212/wnl.51.6.1546

34. Levy R, Dubois B. Apathy and the functional anatomy of the prefrontal cortex-basal ganglia circuits. Cereb Cortex. 2006;16(7):916-928. doi:10.1093/cercor/bhj043

35. Gorno-Tempini ML, Rankin KP, Woolley JD, Rosen HJ, Phengrasamy L, Miller BL. Cognitive and behavioral profile in a case of right arterior temporal lobe neurodegeneration. Cortex. 2004;40(4-5):631644. doi:10.1016/S0010-9452(08)70159-X

36. Vonk JMJ, Borghesani V, Battistella G, et al. Verbal semantics and the left dorsolateral anterior temporal lobe: a longitudinal case of bilateral temporal degeneration. Aphasiology. 2019;00(00):1-21. doi:10.1080/02687038.2019.1659935

37. Dunn L.M. LM\& D. Peabody Picture Vocabulary Test-Revised. Circle Pines, MN: American Guidance Service; 1981.

38. Kaplan E, Goodglass H, Wintraub S. The Boston Naming Test. Philadelphia: Lea and Febiger; 1983.

39. Howard D, Patterson K. Pyramids and Palm Trees: A Test of Semantic Access from Pictures and Words. Bury St Edmunds, Suffolk: Thames Valley Publishing Company; 1992.

40. Benton AL, Van Allen MW. Impairment in facial recognition in patients with cerebral disease. Trans Am Neurol Assoc. 1968;93:38-42.

41. Froming KB, Ekman P, Levy M. Comprehensive Affect Testing System. 2001. 
42. McDonald S. Exploring the process of inference generation in sarcasm: a review of normal and clinical studies. Brain Lang. 1999;68(3):486-506. doi:10.1006/brln.1999.2124

43. Shany-Ur T, Poorzand P, Grossman SN, et al. Comprehension of insincere communication in neurodegenerative disease: Lies, sarcasm, and theory of mind. Cortex. 2012;48(10):1329-1341. doi:10.1016/j.cortex.2011.08.003

44. Gorno-Tempini ML, Rankin KP, Woolley JD, Rosen HJ, Phengrasamy L, Miller BL. Cognitive and behavioral profile in a case of right arterior temporal lobe neurodegeneration. Cortex. 2004;40(4-5):631644. doi:10.1016/S0010-9452(08)70159-X

45. Davis MH. Measuring individual differences in empathy: Evidence for a multidimensional approach. $J$ Personal Soc Psychol. 1983;44(1).

46. Lennox RD, Wolfe RN. Revision of the Self-Monitoring Scale. J Pers Soc Psychol. 1984;46(6):13491364. doi:10.1037/0022-3514.46.6.1349

47. Wiggins JS, Coutu J. Interpersonal Adjective Scales (IAS) Scoring Program [Computer Software]. 1995.

48. Carver CS, White TL. Behavioral inhibition, behavioral activation, and affective responses to impending reward and punishment: The BIS/BAS Scales. J Pers Soc Psychol. 1994;67(2):319-333. doi:10.1037/0022-3514.67.2.319

49. Ossenkoppele R, Cohn-Sheehy BI, La Joie R, et al. Atrophy patterns in early clinical stages across distinct phenotypes of Alzheimer's disease. Hum Brain Mapp. 2015;36(11):4421-4437. doi: $10.1002 / \mathrm{hbm} .22927$

50. La Joie R, Perrotin A, Barré L, et al. Region-specific hierarchy between atrophy, hypometabolism, and 2-amyloid (A $\beta$ ) load in Alzheimer's disease dementia. J Neurosci. 2012;32(46):16265-16273. doi:10.1523/JNEUROSCI.2170-12.2012

51. Spina S, Brown JA, Deng J, et al. Neuropathological correlates of structural and functional imaging biomarkers in 4-repeat tauopathies. Brain. 2019;142(7):2068-2081. doi:10.1093/brain/awz122

52. McKeith IG. Consensus guidelines for the clinical and pathologic diagnosis of dementia with Lewy bodies (DLB): report of the Consortium on DLB International Workshop. J Alzheimers Dis. 2006;9(3 Suppl):417-423.

http://www.ncbi.nlm.nih.gov/entrez/query.fcgi? $\mathrm{cmd}=$ Retrieve \&db=PubMed\&dopt=Citation\&list_uids= 16914880

53. Mackenzie IRA, Neumann M, Baborie A, et al. A harmonized classification system for FTLD-TDP pathology. Acta Neuropathol. 2011;122(1):111-113. doi:10.1007/s00401-011-0845-8

54. Montine TJ, Phelps CH, Beach TG, et al. National Institute on Aging-Alzheimer's Association guidelines for the neuropathologic assessment of Alzheimer's disease: a practical approach. Acta Neuropathol. 2012;123(1):1-11. doi:10.1007/s00401-011-0910-3

55. Josephs KA, Whitwell JL, Knopman DS, et al. Two distinct subtypes of right temporal variant frontotemporal dementia. Neurology. 2009;73(18):1443-1450.

http://www.ncbi.nlm.nih.gov/entrez/query.fcgi?cmd=Retrieve\&db=PubMed\&dopt=Citation\&list_uids= 19884571.

56. Spinelli EG, Mandelli ML, Miller ZA, et al. Typical and atypical pathology in primary progressive aphasia variants. Ann Neurol. 2017;81(3):430-443. doi:10.1002/ana.24885

57. Decety J, Jackson PL. A social-neuroscience perspective on empathy. Curr Dir Psychol Sci. 2006;15(2):54-58. doi:10.1111/j.0963-7214.2006.00406.x

58. Shdo SM, Ranasinghe KG, Gola KA, et al. Deconstructing empathy: Neuroanatomical dissociations between affect sharing and prosocial motivation using a patient lesion model. Neuropsychologia. 2018;116(September 2016):126-135. doi:10.1016/j.neuropsychologia.2017.02.010

59. Hutchings R, Palermo R, Piguet O, Kumfor F. Disrupted Face Processing in Frontotemporal Dementia: A Review of the Clinical and Neuroanatomical Evidence. Neuropsychol Rev. 2017;27(1):18-30. doi:10.1007/s11065-016-9340-2

60. Binney RJ, Henry ML, Babiak M, et al. Reading words and other people: A comparison of exception word, familiar face and affect processing in the left and right temporal variants of primary progressive aphasia. Cortex. 2016;82:147-163. doi:10.1016/j.cortex.2016.05.014 
medRxiv preprint doi: https://doi.org/10.1101/2021.06.07.21258432; this version posted June 10, 2021. The copyright holder for this preprint

(which was not certified by peer review) is the author/funder, who has granted medRxiv a license to display the preprint in perpetuity.

All rights reserved. No reuse allowed without permission.

61. Somerville LH, Fani N, McClure-Tone EB. Behavioral and neural representation of emotional facial expressions across the lifespan. Dev Neuropsychol. 2011;36(4):408-428. doi:10.1080/87565641.2010.549865

62. Ecker C, Suckling J, Deoni SC, et al. Brain anatomy and its relationship to behavior in adults with autism spectrum disorder: A multicenter magnetic resonance imaging study. Arch Gen Psychiatry. 2012;69(2):195-209. doi:10.1001/archgenpsychiatry.2011.1251

63. Younes K, Miller BL. Neuropsychiatric Aspects of Frontotemporal Dementia. Psychiatr Clin North Am. 2020. doi:10.1016/j.psc.2020.02.005

64. McManus C. Half a century of handedness research: Myths, truths; fictions, facts; backwards, but mostly forwards. Brain Neurosci Adv. 2019;3:239821281882051. doi:10.1177/2398212818820513

65. Miller ZA, Mandelli ML, Rankin KP, et al. Handedness and language learning disability differentially distribute in progressive aphasia variants. Brain. 2013;136(Pt 11):3461-3473. doi:10.1093/brain/awt242

66. Rogalski EJ, Saxon M, McKenna H, et al. Communication Bridge: A pilot feasibility study of Internetbased speech-language therapy for individuals with progressive aphasia. Alzheimer's Dement (New York, N Y). 2016;2(4):213-221. doi:10.1016/j.trci.2016.08.005 
Table 1: Demographics, functional, and cognitive scores

\begin{tabular}{|c|c|c|c|c|c|c|}
\hline & $\begin{array}{l}\text { Autopsy } \\
\text { Group }\end{array}$ & $\begin{array}{l}\text { z- } \\
\text { score }\end{array}$ & Living Group & $\begin{array}{c}\text { z- } \\
\text { score }\end{array}$ & Total & $\begin{array}{c}\text { z- } \\
\text { score }\end{array}$ \\
\hline \multicolumn{7}{|l|}{ Epidemiology and Functional Scales } \\
\hline Handedness, (right, left, ambidextrous) & 17,2 & & $22,4,1$ & & $39,6,1$ & \\
\hline Gender, (female, male) & 8,11 & & 14,13 & & 22,24 & \\
\hline Ethnicity (n ethnicity) & $18 \mathrm{~W}, 1 \mathrm{Ch}$ & & $24 \mathrm{~W}, 3 \mathrm{Ch}$ & & 42,4 & \\
\hline Age of onset, mean (sd, n) & $59.3(7.1,19)$ & & $61.4(9.3,27)$ & & $60.2(8.2,46)$ & \\
\hline Age at evaluation, mean $(\mathrm{sd}, \mathrm{n})$ & $62.0(5.8,19)$ & & $67.3(7.9,27)$ & & $65.8(7.6,46)$ & \\
\hline Age deceased, mean $(\mathrm{sd}, \mathrm{n})$ & $69.0(6.2,19)$ & & NA & & NA & \\
\hline Years of education, mean (sd, n) & $16.0(3.1,19)$ & & $15.8(2.9,26)$ & & $15.7(3.0,45)$ & \\
\hline CDR score, mean (sd, n), $\max =3$ & $1.0(0.8,19)$ & & $0.8(0.4,25)$ & & $0.9(0.5,44)$ & \\
\hline CDR Box Score, mean (sd, n), $\max =18$ & $6.0(4.3,19)$ & & $4.2(2.6,25)$ & & $5.0(3.3,44)$ & \\
\hline $\begin{array}{l}\text { NPI Total (severity*frequency), mean }(s d, n), \max = \\
144\end{array}$ & $37.0(25.0,19)$ & & $\begin{array}{l}35.1(16.8 \\
26)\end{array}$ & & $36.0(20.4,45)$ & \\
\hline NPI Caregiver Distress Total, mean (sd, n), $\max =60$ & $18.0(9.7,19)$ & & $12.7(8.4,26)$ & & $14.9(9.3,45)$ & \\
\hline FAQ, mean $(\mathrm{sd}, \mathrm{n}), \max =30$ & $13.0(7.2,19)$ & & $12.0(8.0,25)$ & & $12.2(7.7 .44)$ & \\
\hline \multicolumn{7}{|l|}{ Global Cognition } \\
\hline MMSE, mean (sd, n), $\max =30$ & $25.9(3.3,19)$ & -3.4 & $24.3(5.4,27)$ & -5.0 & $25.0(4.7,46)$ & -4.8 \\
\hline \multicolumn{7}{|l|}{ Visuospatial Processing } \\
\hline $\begin{array}{l}\text { Benson complex figure - copy, mean (sd, n), max = } \\
17\end{array}$ & $14.8(2.7,19)$ & -0.7 & $14.9(1.6,26)$ & -0.6 & $14.9(2.1,45)$ & -0.9 \\
\hline VOSP Number Location, mean (sd, n), $\max =10$ & $8.2(4.4,18)$ & -1.0 & $8.5(2.5,24)$ & -0.8 & $8.4(3.4,42)$ & -1.1 \\
\hline \multicolumn{7}{|l|}{ Episodic Memory } \\
\hline $\begin{array}{l}\text { CVLT } 30 " \text { short delay free recall, mean }(\mathrm{sd}, \mathrm{n}), \max = \\
9\end{array}$ & $4.3(2.6,18)$ & -2.3 & $4.1(2.6,23)$ & -2.4 & $4.2(2.6,41)$ & -2.4 \\
\hline CVLT $10^{\prime}$ long delay free recall, mean $(\mathrm{sd}, \mathrm{n}), \max =9$ & $4(2.6,18)$ & -2.4 & $2.5(2.7,23)$ & -3.0 & $3.0(2.7,41)$ & -2.8 \\
\hline CVLT Recognition, mean (sd, n), $\max =9$ & $6.3(2.4,18)$ & -2.8 & $6.5(2.1,23)$ & -2.5 & $6.4(2.2,41)$ & -2.8 \\
\hline $\begin{array}{l}\text { Benson complex figure - delay, mean (sd, n), } \max = \\
17\end{array}$ & $6.2(4.4,18)$ & -2.6 & $4.8(4.5,26)$ & -3.0 & $5.4(4.5,44)$ & -2.9 \\
\hline \multicolumn{7}{|l|}{ Executive Functioning } \\
\hline Digit Span - backward, mean (sd, n) & $4.9(1.3,18)$ & 0.0 & $5.2(1.6,26)$ & 0.3 & $5.1(1.5,45)$ & 0.1 \\
\hline Stroop (correct in 60 seconds), mean (sd, n) & $47.7(26.5,11)$ & -2.1 & $\begin{array}{l}46.0(11.9 \\
20)\end{array}$ & -2.2 & $46.6(18.0,31)$ & -2.9 \\
\hline Trails (Time), mean (sd, n), $\max =120^{\prime \prime}$ & $67.2(34.4,19)$ & -3.7 & $\begin{array}{l}59.0(68.0 \\
22)\end{array}$ & -2.9 & $37.4(36.5,41)$ & 0.8 \\
\hline Design fluency, mean (sd, n) & $6.8(2.4,17)$ & -1.3 & $6.4(3.6,24)$ & -1.5 & $6.6(3.1,41)$ & -1.5 \\
\hline \multicolumn{7}{|l|}{ Language } \\
\hline Verbal agility, mean (sd, n), $\max =5$ & $4.7(1.4,12)$ & -0.9 & $5.6(0.9,21)$ & 0.1 & $5.2(1.2,33)$ & -0.5 \\
\hline Repetition, mean (sd, n), max =5 & $4.2(0.9,13)$ & -0.1 & $4.0(1.0,23)$ & -0.3 & $4.1(1.0,36)$ & -0.4 \\
\hline WRAT-4 Reading, mean (sd, n), $\max =70$ & $53.3(15.4,8)$ & & $56.1(9.2,21)$ & & $53.3(15.4,8)$ & \\
\hline Apraxia of speech rating, mean (sd, n), $\max =7$ & $0.0(0.0,11)$ & & $0.0(0.0,21)$ & & $0.0(0.0,31)$ & \\
\hline Dysarthria rating, mean $(\mathrm{sd}, \mathrm{n}), \max =7$ & $0.0(0.0,11)$ & & $0.0(0.0,21)$ & & $0.1(0.2,31)$ & \\
\hline Syntax Comprehension, mean (sd, n), $\max =5$ & $4.6(0.7,12)$ & -0.1 & $4.4(1.1,23)$ & 0.4 & $4.5(1.0,35)$ & -0.5 \\
\hline Lexical fluency - \# in 60", mean (sd, n) & $7.1(2.8,19)$ & $-1.9 *$ & $10.6(5.1,24)$ & $-1 *$ & $9.1(4.5,43)$ & -1.5 \\
\hline
\end{tabular}

Descriptive statistics presented for the demographic, functional, global cognition, visuospatial, verbal and visual memory, and executive tasks of the Autopsy and Living Groups. * = Autopsy Group and Living Group are significantly statistically different $\mathrm{p}<.05$. Bold represents results less than 1.5 standard deviation below the mean and are considered clinically abnormal results. $\mathrm{CDR}=$ Clinical Dementia Rating; $\mathrm{W}=$ White; $\mathrm{Ch}=\mathrm{Chinese}$; CVLT = California Verbal Learning Test; FAQ = Functional Activities Questionnaire; MMSE = Mini Mental State Exam; NPI = Neuropsychiatric Inventory; NA = Not Applicable; VOSP = Visual Object and Space Perception Battery. 
medRxiv preprint doi: https://doi.org/10.1101/2021.06.07.21258432; this version posted June 10, 2021. The copyright holder for this preprint (which was not certified by peer review) is the author/funder, who has granted medRxiv a license to display the preprint in perpetuity.

All rights reserved. No reuse allowed without permission.

Table 2: Language and socioemotional profile

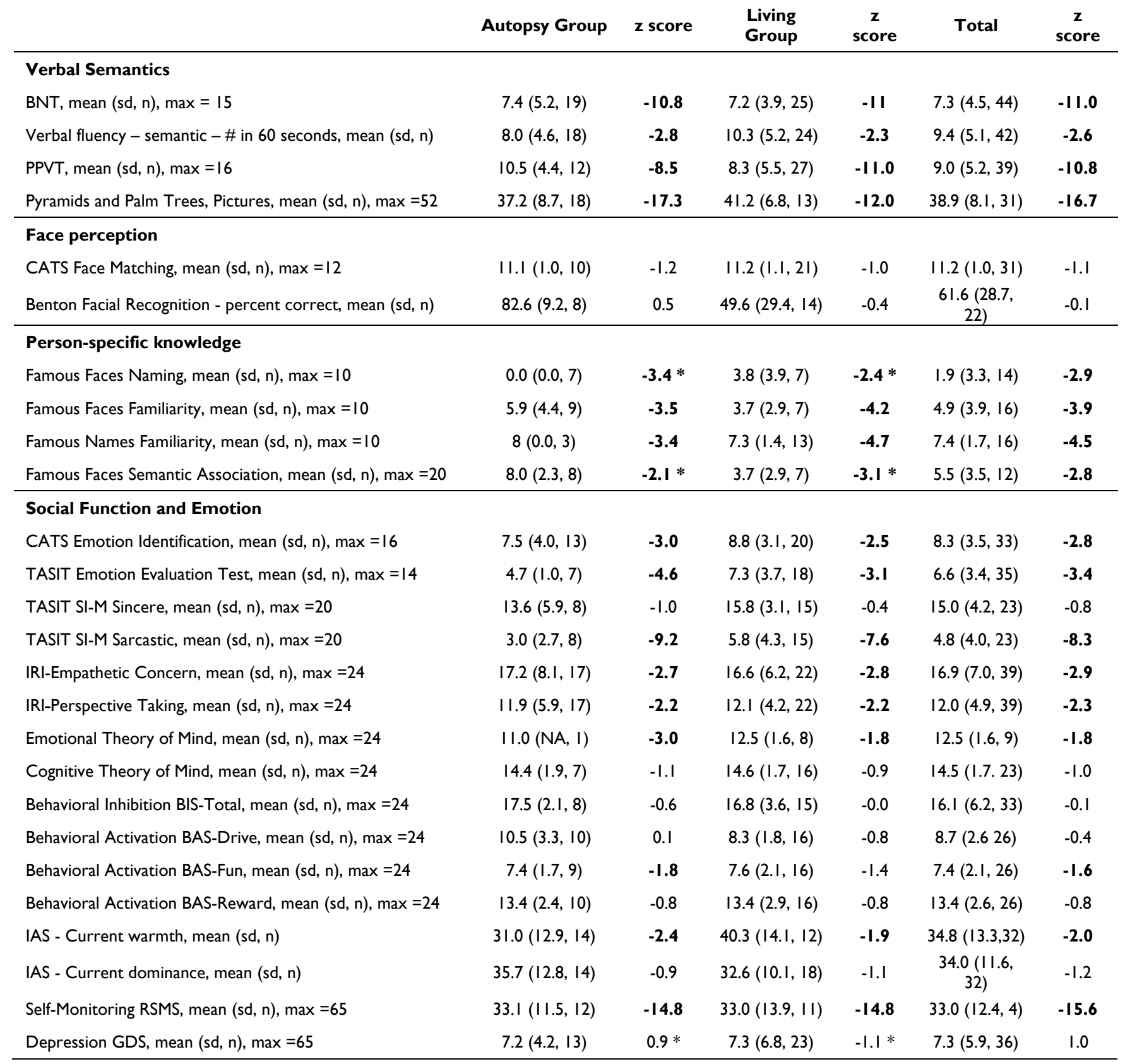

Autopsy Group (total $n=19$ ) and Living Group (total $n=27) . *$ Autopsy Group and Living Group are significantly statistically different $\mathrm{p}<.05$. Bold represents results less than 1.5 standard deviation below the mean and are considered clinically abnormal results. BNT = Boston Naming Test; PPVT = Peabody Picture Vocabulary Test; CATS $=$ Comprehensive Affect Testing System; TASIT $=$ The Awareness of Social Inference Test; EET = Emotion Evaluation Test; IRI = Interpersonal Reactivity Index; EC = Empathic Concern; PT = Perspective Taking; IAS = Interpersonal Adjective Scales; RSMS = Revised Self-Monitoring Scale. GDS = Geriatric Depression Scale. $*=$ Autopsy Group and Living Group are statistically different $p<.05$. Might want to write somewhere Z-scores worse than -1.5 in bold. 
medRxiv preprint doi: https://doi.org/10.1101/2021.06.07.21258432; this version posted June 10, 2021. The copyright holder for this preprint (which was not certified by peer review) is the author/funder, who has granted medRxiv a license to display the preprint in perpetuity.

All rights reserved. No reuse allowed without permission.

Table 3: Primary pathology in the 19 pathology-proven cases (Autopsy Group)

\begin{tabular}{|c|c|c|c|c|}
\hline & $\mathrm{n},(\%)$ & Genetic mutation & $\begin{array}{c}\text { Age at onset (years) } \\
\text { mean (median, } \\
\text { range) }\end{array}$ & $\begin{array}{l}\text { Survival (years) } \\
\text { mean (median, } \\
\text { range) }\end{array}$ \\
\hline FTLD-TDP Type-C & $13,(68 \%)$ & Absent & $57(59,44-65)$ & $13(13,7-18)$ \\
\hline FTLD-tau Pick's type & $2,(10 \%)$ & Absent & $52(52,51-53)$ & $5(5,4-6)$ \\
\hline FTLD-TDP-Type-B with MND & $\mathrm{I},(5 \%)$ & Absent & 55 & 9 \\
\hline FTLD-TDP-Type A & $\mathrm{I},(5 \%)$ & Absent & 60 & 12 \\
\hline FTLD-TDP-U with MND & $\mathrm{I},(5 \%)$ & Absent & 58 & 15 \\
\hline FTLD-tau unclassifiable $4 R$ tauopathy & $\mathrm{I},(5 \%)$ & Absent & 69 & 10 \\
\hline
\end{tabular}

Count and percentage of primary pathology found in the predominant right temporal atrophy, age at symptoms onset, and survival years are presented for each pathological diagnosis. FTLD =Frontotemporal lobar degeneration. TDP-43 =TAR DNA binding protein. FTLD-TDP-U =FTLD-TDP (unspecified). MND=motor neuron disease. Details of each case is presented in Supplementary table 4.

Table 4: Proposed diagnostic criteria for semantic emotional variant frontotemporal dementia (esvFTD)

I. Patient shows gradually progressive deterioration by history and/or testing

\section{Possible esvFTD}

Patient must have 2 out of \# A - C and I out of \# D - F

\section{CORE FEATURES}

A. Loss of empathy (difficulty understanding emotions)

B. Difficulty identifying and naming known people

C. Complex compulsions or rigid thought process

\section{SUPPORTIVE FEATURES}

D. Object naming difficulties

E. Spared visuospatial functions including preserved perceptual matching and drawing reproduction

F. Spared motor speech and phonology

\section{Probable esvFTD:}

All of the following must be present:

A. Meets criteria for possible esvFTD

B. Imaging results consistent with esvFTD:

I - Right anterior temporal lobe volume loss and relative sparing of the frontal cortex on MRI or CT

2- Right anterior temporal lobe hypometabolism and relative sparing of the frontal cortex on FDG-PET 


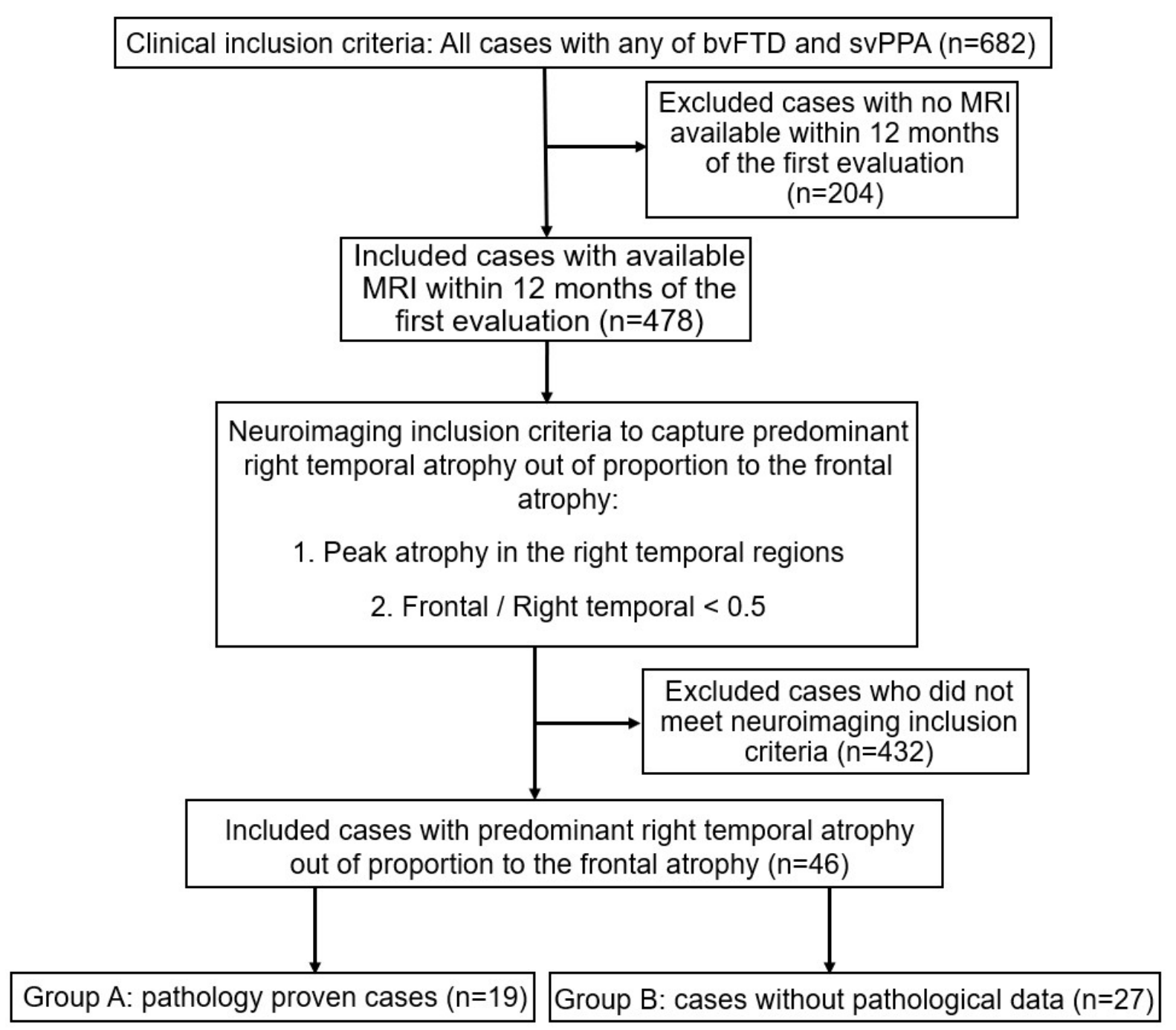

Figure 1 Patient selection. We searched the University of California, San Francisco Memory and Aging Center database. The first inclusion criteria was clinical diagnosis, we included all participants who received a clinical diagnosis of behavioral variant frontotemporal dementia or semantic variant primary progressive aphasia. We then excluded all patients who did not have a brain MRI within one year of the first research evaluation. Next, we included participants who had peak atrophy in the right temporal lobe on a brain MRI W-score map and showed predominantly right temporal atrophy out of proportion to the frontal atrophy, on quantitative imaging-based index (46 participants). This resulted in 19 path-proven cases and 27 without pathological data cases. FTD $=$ frontotemporal dementia spectrum disorders; PPA = primary progressive aphasia 


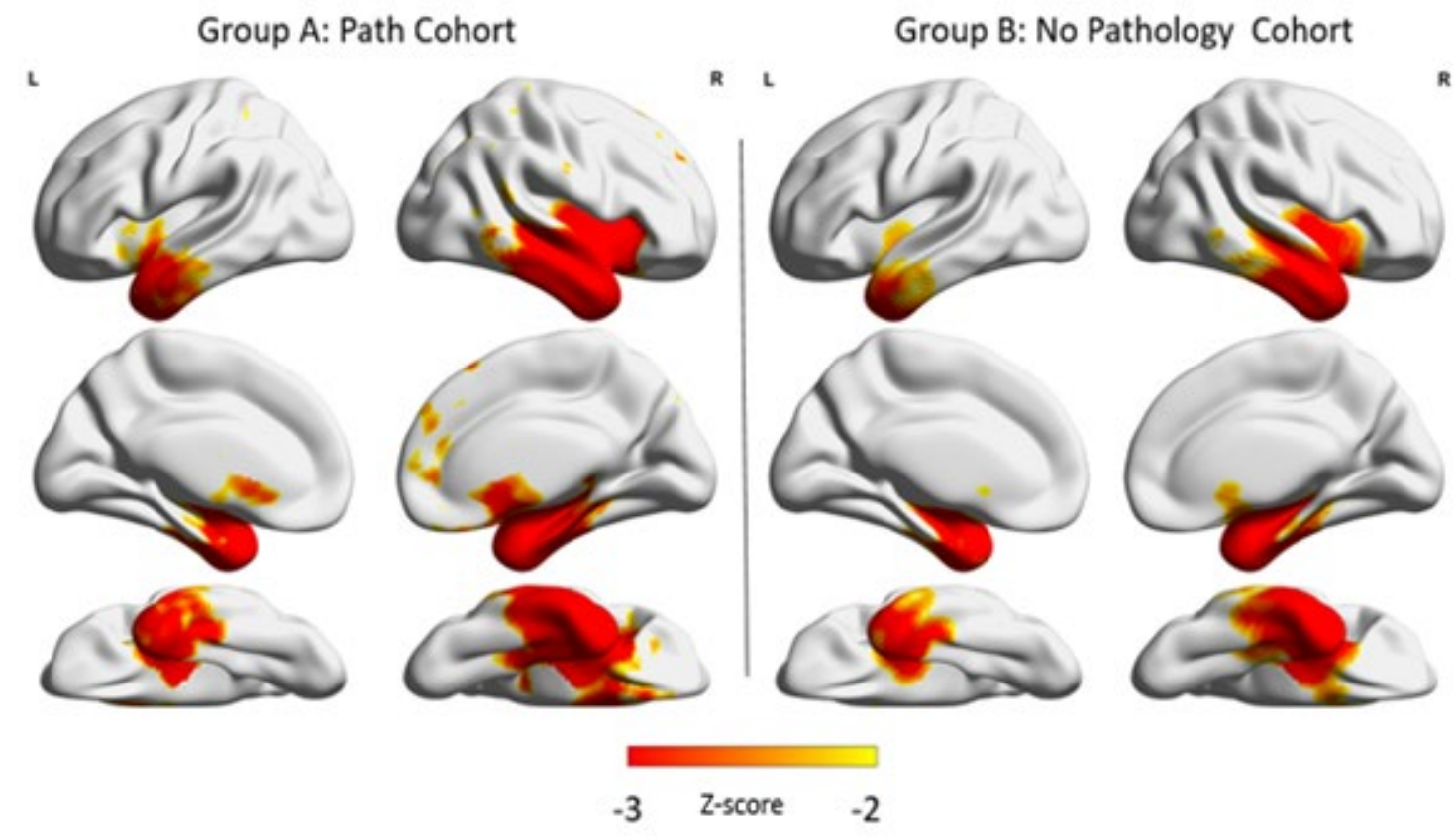

Figure 2 Neuroimaging in right temporal neurodegeneration. Lateral, mesial, and inferior views. Predominant right temporal atrophy was used as part of the inclusion criteria based on neuroimaging data-driven approach. All participants included, exhibited maximum atrophy in the right temporal lobe more than the left anterior temporal lobe with involvement of the right more than left insula, right caudate, and right more than left subgenual anterior cingulate cortex. The pathology proven cohort (Autopsy Group; $n=19$ ) had scattered right mesial and dorslateral prefrontal cortex volume loss that was not present in the group without pathology data (Living Group; $n=27$ ). Notably there is sparing of the frontal, parietal, and occipital lobes. 

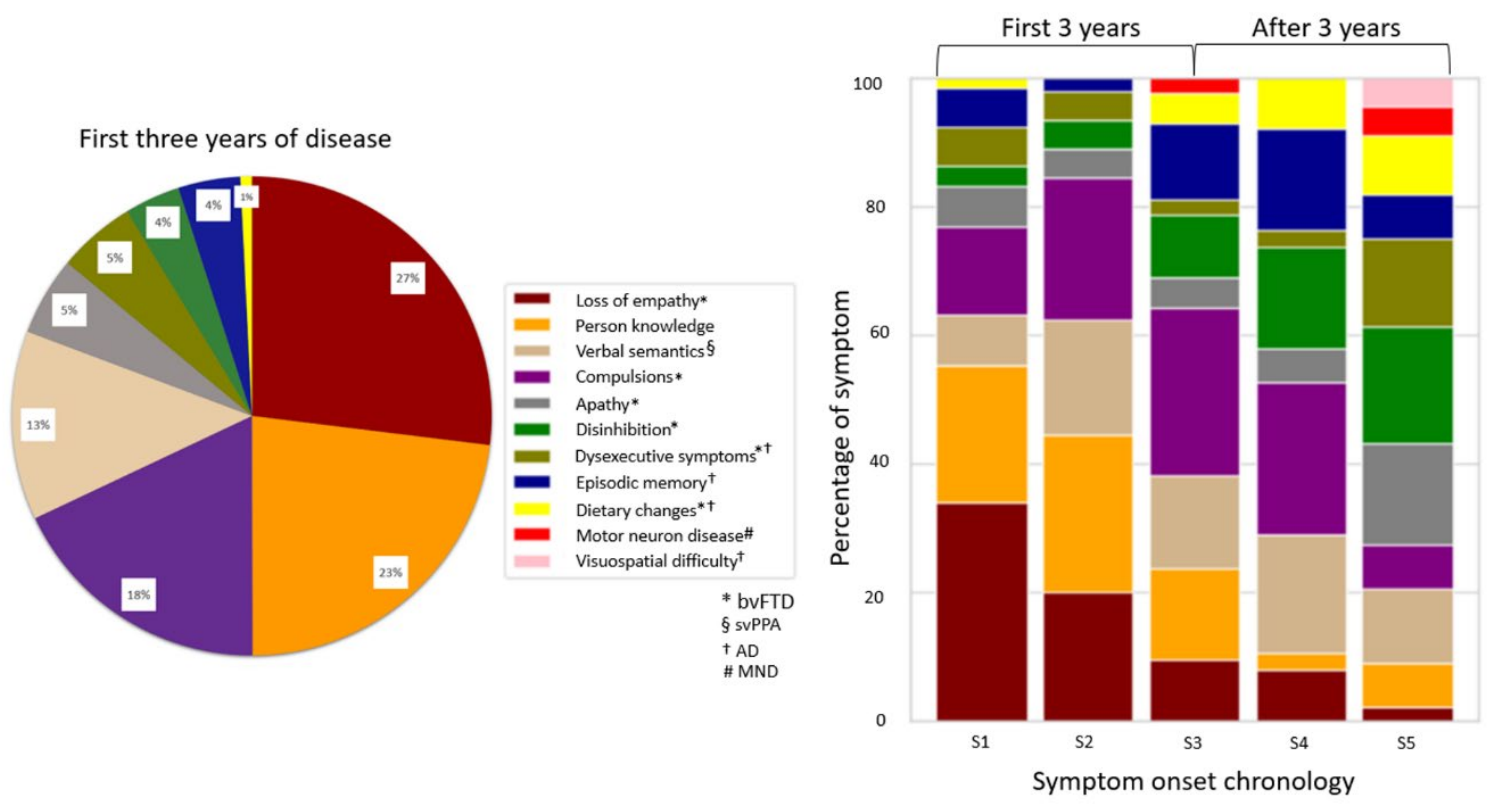

Figure 3 Chronology of symptoms. (A) shows the percentage of symptoms in the first three years of the illness. (B) shows the chronology of new symptoms in the order of their occurrence. The most common symptoms during the first three years of disease onset are loss of empathy, loss of semantic knowledge, and compulsive behaviors and rigid thought process. Disinhibition, apathy, and dietary changes happened later. S1: first symptom; S2: second symptom, S3: third symptom; S4: fourth symptom; S5: fifth symptom; *: symptom belongs to the bvFTD criteria; \#: symptom belongs to the bvFTD criteria; §: symptom belongs to the svPPA criteria; $\uparrow$ : symptom belongs to the Alzheimer`s disease diagnostic criteria; $\perp$ : symptom belongs to the amyotrophic lateral sclerosis diagnostic criteria. 